\title{
Calcium Silicate-Based Experimental Sealers: Physicochemical Properties Evaluation
}

\author{
Cristiane Lopes Zordan-Bronzel ${ }^{a}$ (D), Mario Tanomaru-Filho ${ }^{a}$ (D), Gisselle Moraima Chávez-Andrade ${ }^{a}$ \\ (D), Fernanda Ferrari Esteves Torres ${ }^{a}$ (D), Giselle Priscilla Cruz Abi-Rached ${ }^{a}$, \\ Juliane Maria Guerreiro-Tanomaru ${ }^{a}$ (D) \\ ${ }^{a}$ Universidade Estadual Paulista (UNESP), Faculdade de Odontologia de Araraquara, Departamento \\ de Odontologia Restauradora, Araraquara, SP, Brasil
}

Received: June 04, 2020; Revised: September 28, 2020; Accepted: October 11, 2020

\begin{abstract}
The aim of this study was to evaluate physicochemical properties of calcium silicate-based experimental (CS) endodontic sealers, developed using two different vehicles: polyethylene glycol (PG) (CS-PG) or polyethylene glycol associated to chitosan hydrogel (CS-PGCH). TotalFill BC Sealer (TF) and AH Plus (AHP) were evaluated for comparison. Setting time, flow, radiopacity, $\mathrm{pH}$, solubility and volumetric change were analyzed. Data were submitted to ANOVA and Tukey tests with 5\% significance level. The CS-PGCH had significantly greater setting time. CS-PG flow was similar to AHP. CS-PG had higher radiopacity than CS-PGCH. Calcium silicate-based sealers presented alkaline $\mathrm{pH}$ in all periods. CS-PGCH presented higher solubility in comparison with CS-PG. The volumetric change of CS-PG was similar to TF after 7 days, and to AHP after 30 days. CS-PG presented proper setting time, radiopacity, flow and $\mathrm{pH}$, besides low volumetric change, showing better results than CS-PGCH, and potential for clinical application.
\end{abstract}

Keywords: Biocompatible Materials, Calcium Silicate, X-Ray Microtomography, Dental Materials, Physical Properties.

\section{Introduction}

Calcium silicate-based materials were developed as repair cements ${ }^{1}$. The presence of tricalcium silicate increases mechanical properties and bioactivity of the materials ${ }^{2}$. Currently, calcium silicate materials are widely used as root canal sealers ${ }^{3,4}$. However, in order to provide improved physicochemical properties and flow for calcium silicate materials, new formulations are proposed ${ }^{1}$, using different vehicles to obtain adequate consistency for clinical applicability ${ }^{5}$. Polyethylene glycol is traditionally used as vehicle for calcium hydroxide pastes ${ }^{6}$. Bio-C Sealer is a new ready-to-use bioceramic endodontic sealer that contains polyethylene glycol as vehicle and presents biocompatibility, bioactive potential ${ }^{7}$ and suitable physicochemical properties for clinical use ${ }^{8}$. EndoSequence BC (Brasseler, Savannah, GA, USA) and TotalFill BC (FKG, La Chaux-de-Fonds, Switzerland) are also premixed bioceramic sealers, which have similar composition, ${ }^{3,9}$. These sealers present suitable properties $^{8,9}$, such as cytocompatibility ${ }^{10}$, biocompatibility ${ }^{11}$, bioactivity ${ }^{12}$ and antimicrobial activity ${ }^{13}$.

New root canal filling materials are developed, composed by calcium silicates, radiopacifying agents, and a vehicle to obtain ideal characteristics. A previous study ${ }^{13}$ evaluating an experimental calcium silicate-based endodontic sealer with polyethylene glycol as vehicle showed cytocompatibility, bioactive potential, and antimicrobial activity, with potential for clinical application. In addition, since failure of endodontic

*e-mail: tanomaru@uol.com.br therapy is related to the persistence of microorganisms in the root canal system ${ }^{14,15}$, root canal sealers should present antimicrobial properties. The association of chitosan as vehicle can promote increased antimicrobial activity ${ }^{16}$, inhibiting bacterial penetration and colonization ${ }^{17}$. This association can also favor the formation of hydroxyapatite ${ }^{16}$ in addition to dentinal biomineralization ${ }^{18}$.

ISO 6876 standard $^{19}$ is used for the evaluation of endodontic sealers. Since the physicochemical properties of the polyethylene glycol or chitosan as vehicles for calcium silicate-based endodontic sealers have not yet been studied, the aim of this study was to develop two experimental endodontic sealers based on tricalcium and dicalcium silicates and evaluate their physicochemical properties. The null hypothesis was that would be no difference among the sealers evaluated regarding these properties.

\section{Experimental}

\subsection{Materials}

The experimental sealers were developed using a powder formulation: tricalcium silicate $(46.55 \%)$, dicalcium silicate $(6.65 \%)$, monobasic calcium phosphate $(5.00 \%)$, calcium hydroxide $(3.80 \%)$ and zirconium oxide $(38.00 \%)$. Five vehicle options were tested: Hydroxyethylcellulose (Natrosol), Polyethylene Glycol (PG), Chitosan hydrogel (CH), Carboxymethylcellulose, $\mathrm{PG}+\mathrm{CH}$. Based on handling property and setting time, two vehicle options were selected: PG, and 
the association $\mathrm{PG} / \mathrm{CH}$. However, the radiopacity presented by these formulations did not comply the specifications of ISO 6879:2012 $2^{19}$ (above $3 \mathrm{~mm} \mathrm{Al}$ ). Therefore, calcium tungstate was added to the base powder to improve the radiopacity. The final formulation was obtained: tricalcium silicate $(46.55 \%)$, dicalcium silicate $(6.55 \%)$, monobasic calcium phosphate $(5.00 \%)$, calcium hydroxide $(3.80 \%)$, zirconium oxide $(28.50 \%)$ and calcium tungstate $(9.50 \%)$. The handling of powder was performed with vehicle options. The proportion of the selected vehicles was determined after flow tests with different proportions.

After the preliminary tests, two experimental sealers were selected to be evaluated in comparison with AH Plus and TotalFill BC. The sealers, their manufacturers, composition and proportions are described in Table 1.

\subsection{Setting time}

The setting time (ST) was evaluated according to the ISO 6876:2012 specifications $^{19}$. Type IV plaster molds (Dentsply, Petrópolis, Rio de Janeiro, Brazil) were made with an internal diameter of $10 \mathrm{~mm}$ and height of $1 \mathrm{~mm}(\mathrm{n}=6)$, and kept in distilled water for 24 hours. The materials were mixed, placed into plaster molds and stored in an oven under moisture control $\left(37 \pm 1{ }^{\circ} \mathrm{C}, 95 \pm 5 \%\right.$ relative humidity). A Gilmore needle with mass of $100 \pm 0.5 \mathrm{~g}$ and diameter of $2 \pm 0.1 \mathrm{~mm}$ was used for determination of the ST. The ST was considered as the period in minutes, between manipulation and the moment at which the needle did not leave indentation on the surface of the sealer, and the materials were stored in the oven throughout this period.

\subsection{Flow}

The flow was analyzed in accordance to the ISO 6876:2012 ${ }^{19}$ standard. After manipulation, $0.05 \mathrm{~mL}$ of the sealer was placed on a glass plate $(n=10)$. Then, another glass plate $(20 \mathrm{~g})$ was placed over the sealer together with a device weighing $100 \mathrm{~g}$, for 10 minutes. Then, the shortest diameter and the longest diameter of the sealer disks were measured using a digital caliper. The mean value was recorded when a difference of less than $1.00 \mathrm{~mm}$ between the diameters was observed. Two methods were used to perform the measurements. For the second method, the specimens were photographed next to a ruler graduated in millimeters. The images obtained were digitized and the area of sealer was measured in $\mathrm{mm}^{2}$ in the UTHSCSA Image Tool for Windows program, Version 3.00, as described by Tanomaru-Filho et al. ${ }^{20}$.

\subsection{Radiopacity}

Specimens with an internal diameter of $10 \mathrm{~mm}$ and $1 \mathrm{~mm}$ height were made of the sealers $(n=6)$. After complete setting $\left(37 \pm 1{ }^{\circ} \mathrm{C}, 95 \pm 5 \%\right.$ relative humidity, 3 times the duration of their setting time), one disc of each material and an aluminum scale were placed on an occlusal film (Insight - Kodak Comp, Rochester, NY) to take a radiograph with a focus X-ray appliance (Instrumentarium Dental, Tuusula, Finland), operated at $60 \mathrm{kV}, 7 \mathrm{~mA}, 18$ pulses/s and focal distance of $33 \mathrm{~cm}$. The films were processed, digitized, and analyzed using Image $J$ for Windows software, in which areas of each of the steps of the millimeter scale were selected to determine the radiopacity equivalence of the sealers in millimeters of aluminum (mm Al). The values obtained were converted as described by Hungaro-Duarte et al. ${ }^{21}$.

\section{$2.5 \mathrm{pH}$}

Polyethylene tubes measuring $10 \mathrm{~mm}$ length and $1.6 \mathrm{~mm}$ in diameter were filled with each material $(n=10)$. Each tube was immersed in a plastic flask with $10 \mathrm{~mL}$ distilled water and stored in at $37 \pm 1{ }^{\circ} \mathrm{C}$. For the control group, distilled water was used. After each experimental period, the tubes were placed in new flasks containing $10 \mathrm{~mL}$ of distilled water. The experimental periods were 3, 12 and 24 hours, 7, 14 and 21 days. The $\mathrm{pH}$ of the water in which the tubes had been kept was measured with a $\mathrm{pH}$ meter (model DM-21, Digimed, São Paulo, SP, Brazil), previously calibrated using buffer solutions of $\mathrm{pH} 4.01,6.86$, and 10.01 (Digimed).

\subsection{Solubility}

Solubility was determined based on Carvalho-Junior et al. ${ }^{22}$ Test specimens $(7.75 \mathrm{~mm}$ in diameter by $1.5 \mathrm{~mm}$ height) were made $(n=6)$, using silicone molds. An impermeable nylon thread was embedded in the fresh sealer mixture. A glass slab covered with cellophane film was placed over the molds. For calcium silicate-based sealers, pieces of damp gauze were placed between the molds and plates, according to a previous study ${ }^{9}$. After complete setting $\left(37 \pm 1{ }^{\circ} \mathrm{C}\right.$, $95 \pm 5 \%$ relative humidity, for a period of three times the

Table 1. Materials, their manufacturer, composition and proportions used.

\begin{tabular}{|c|c|c|}
\hline Sealers & Manufacturer/Composition & Proportion \\
\hline CS-PG ${ }^{\mathrm{a}}$ & $\begin{array}{l}\text { Powder: tricalcium silicate }{ }^{\mathrm{b}}(46.55 \%) \text {, dicalcium silicate }{ }^{\mathrm{b}}(6.65 \%) \text {, calcium phosphate } \\
\text { monobasic }^{\mathrm{c}}(5.00 \%) \text {, calcium hydroxide }(3.80 \%) \text {, zirconium } \text { oxide }^{\mathrm{e}}(28.50 \%) \text { and calcium } \\
\text { tungstate }^{\mathrm{e}}(9.50 \%) \text {. Liquid: polyethylene glycol } 400^{\mathrm{e}} \text {. }\end{array}$ & $\begin{array}{c}1 \mathrm{~g} / 400 \mu \mathrm{L} \\
\text { (powder/liquid) }\end{array}$ \\
\hline CS-PGCH ${ }^{\mathrm{a}}$ & 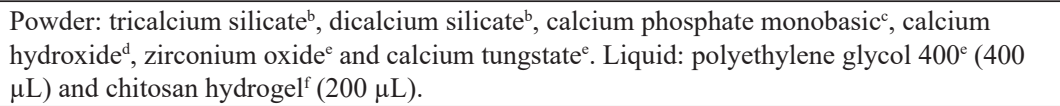 & $\begin{array}{c}1 \mathrm{~g} / 600 \mu \mathrm{L} \\
\text { (powder/liquid) }\end{array}$ \\
\hline TotalFill BC & $\begin{array}{l}\text { Brasseler, Savannah, GA, USA. Lot: 15002SP. Valid. 06.2017. Zirconium oxide, calcium } \\
\text { silicates, calcium phosphate monobasic, calcium hydroxide, filler and thickening agents. }\end{array}$ & Ready to use \\
\hline AH Plus & $\begin{array}{l}\text { Dentsply DeTrey GmbH, Konstanz, Germany. Lot: } 1994151 \text { Valid. 02.2018. Bisphenol A/F } \\
\text { epoxy resin, calcium tungstate, zirconium oxide, silica, iron oxide pigments dibenzyldiamine, } \\
\text { aminoadamantane, silicone oil. }\end{array}$ & $\begin{array}{c}1 \mathrm{~g} / 1 \mathrm{~g} \\
\text { (Paste/paste) }\end{array}$ \\
\hline
\end{tabular}

Experimental calcium silicate-base sealer manipulated with polyethylene glycol (CS-PG); Experimental calcium silicate-base sealer manipulated with

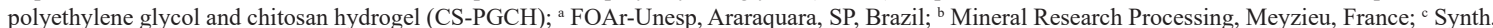
Diadema, SP, Brazil; ${ }^{\mathrm{d}}$ Merck, Darmstadt, Germany; ${ }^{\mathrm{e}}$ Sigma-Aldrich, St. Louis, MO, USA; ${ }^{\mathrm{f}}$ Araraquara School of Pharmaceutical Sciences (FCFAR), UNESP, Araraquara, SP, Brazil. 
duration of their setting time), the specimens were removed from their molds, placed in a dehumidifier under vacuum. The mass was measured before and after the specimens were immersed in distilled water with a precision balance (Analítica Adventurer, Model AR2140, Ohaus - Indústria de Balanças Ltda., São Bernardo do Campo, SP, Brazil). The specimens were attached to the closed plastic flasks, containing $7.5 \mathrm{~mL}$ of distilled water, with nylon threads and kept in an oven at $37 \pm 1{ }^{\circ} \mathrm{C}$ for 7 and 30 days. The solubility (mass loss) was expressed as a percentage of the original mass.

\subsection{Volumetric change}

The experimental sealer with suitable physicochemical properties for clinical use (CS-PG) was selected for additional evaluation of volumetric change, as well as for future studies. The analysis was performed based on a previous study ${ }^{8}$, TotalFill BC and AH Plus were used for comparison. The specimens $(n=6)$ with a diameter of $7.75 \mathrm{~mm}$ by $1.50 \mathrm{~mm}$ in height were prepared and kept in an oven at $37 \pm 1{ }^{\circ} \mathrm{C}$ and relative humidity for 3 times the duration of their setting time. Then, the specimens were scanned by microcomputed tomography SkyScan 1176 (Bruker-MicroCT, Kontich, Belgium). After 7 and 30 days of immersion in distilled water, the samples were placed in a dehumidifier for 24 hours and after this period the specimens were scanned again. The scanning parameters were: $80 \mathrm{kV}$ voltage, $300 \mu \mathrm{A}$ current, $18 \mu \mathrm{m}$ voxel size, copper and aluminum $(\mathrm{Cu}+\mathrm{Al})$ filter and $360^{\circ}$ rotation. The reconstruction of the images was performed using NRecon software (V1.6.10.4; BrukerMicroCT, Kontich, Belgium). The correction parameter for smoothing, beam hardening, and ring artifacts were defined for each material. The same parameters were used for the same material in the different periods. The reconstructed images were superimposed on the different periods using the Data Viewer software (V1.5.2.4; Bruker-MicroCT, Kontich, Belgium). The 3D images were used for quantitative analysis of the samples, allowing the total volume of material to be calculated in $\mathrm{mm}^{3}$ by CTAn software (V1.15.4.0; BrukerMicroCT, Kontich, Belgium). The volumetric change between the baseline and the experimental periods was calculated.

\subsection{Statistical analysis}

The normality of the data was tested using the KolmogorovSmirnov test. Data were submitted to one-way ANOVA and Tukey or Student's t-tests, with 5\% significance level.

\section{Results and Discussion}

Properties of endodontic materials are directly related to the successful root canal treatment ${ }^{23}$. AH Plus (Dentsply DeTrey GmbH, Konstanz, Germany) is an epoxy resin-based sealer, considered as gold standard due to its physicochemical properties $^{24}$. Therefore, AH Plus, and TotalFill BC, a calcium silicate-based sealer, were evaluated for comparison. The present study assessed two experimental calcium silicatebased sealers manipulated with polyethylene glycol. Both sealers presented proper consistency and promoted an alkaline $\mathrm{pH}$. However, the addition of chitosan impaired some sealer properties, rejecting our null hypothesis.

Polyethylene glycol (PG) as vehicle for calcium hydroxide-based intracanal medication ${ }^{6}$ allows diffusion of $\mathrm{Ca}^{2+}$ and $\mathrm{OH}^{-}$ions into root dentin ${ }^{25}$. Polymers such as PG may potentially improve physicochemical properties of silicate materials ${ }^{26}$. PG added to a calcium phosphate-based material (1\% ICPC) provided stability, increased viscosity, and allowed cell proliferation ${ }^{27}$. The new bioceramic Bio-C Sealer (Angelus, PR, Brazil) was developed including PG in its composition. Bio-C Sealer has alkalinization ability, suitable flow and radiopacity ${ }^{8}$, beside biocompatibility and bioactive potential ${ }^{7}$. For this reason, based on a previous study that showed the setting reaction of this new sealer ${ }^{8}$, PG was used as a vehicle for the development of the experimental sealers.

Chitosan was added to the PG in the second experimental sealer (CS-PGCH) aiming to increase antimicrobial activity ${ }^{17}$ and bioactive potential ${ }^{16}$. A previous study ${ }^{16}$ developed experimental calcium silicate-based sealers manipulated with dicalcium phosphate and chitosan polymer. Although the addition of chitosan did not influence the bioactivity of the materials, an increase in their setting time was observed ${ }^{16}$, in agreement with our findings. Since the setting of calcium silicate-based materials depends on moisture ${ }^{28}$, the present study used plaster molds to keep this necessary humidity. Our results showed that the experimental sealers, and TotalFill BC presented highest setting times (Table 2) even in the presence of humidity ${ }^{29,30}$, as observed in previous studies ${ }^{29,30}$. The properties of setting time, solubility and $\mathrm{pH}$ are related ${ }^{31}$. Therefore, the calcium silicate-based sealers had the highest setting time and also showed greater $\mathrm{pH}$ and solubility compared to the epoxy resin-based sealer, AH Plus $(p<0.05)$.

After 7 days of immersion in distilled water, the experimental sealers had significantly higher solubility (Table 2) in comparison with AH Plus and TotalFill BC $(p<0.05)$. After 30 days, the experimental sealer with polyethylene glycol presented lower solubility than at 7 days, similar to TotalFill $(p>0.05)$, suggesting a mass stabilization. The results obtained are in accordance with a previous study that observed that experimental sealers containing calcium silicates and calcium phosphate also presented high solubility ${ }^{32}$. iRoot SP (Innovative BioCeramicx, Inc, Burnaby Canada)

Table 2. Setting time, flow, radiopacity, and solubility (mean and standard deviation) observed in the different endodontic sealers.

\begin{tabular}{lcccc}
\hline & AH Plus & TotalFill BC & CS-PG & CS-PGCH \\
\hline Setting time (min) & $384.0( \pm 0.00)^{\mathrm{d}}$ & $590.1( \pm 31.05)^{\mathrm{c}}$ & $785.0( \pm 23.45)^{\mathrm{b}}$ & $870.0( \pm 0.00)^{\mathrm{a}}$ \\
\hline Flow $\left(\mathrm{mm}^{2}\right)$ & $407.2( \pm 114.2)^{\mathrm{b}}$ & $535.4( \pm 52.8)^{\mathrm{a}}$ & $382.8( \pm 42.4)^{\mathrm{b}}$ & $250.5( \pm 46.6)^{\mathrm{c}}$ \\
\hline Flow (mm) & $21.41( \pm 1.14)^{\mathrm{b}}$ & $24.63( \pm 0.57)^{\mathrm{a}}$ & $20.96( \pm 0.64)^{\mathrm{b}}$ & $17.46( \pm 1.39)^{\mathrm{c}}$ \\
\hline Radiopacity (mm Al) & $9.22( \pm 0.44)^{\mathrm{a}}$ & $5.88( \pm 0.67)^{\mathrm{b}}$ & $5.49( \pm 0.39)^{\mathrm{b}}$ & $4.51( \pm 0.50)^{\mathrm{c}}$ \\
\hline Solubility 7 d (\% mass loss) & $0.04( \pm 0.48)^{\mathrm{d}}$ & $7.48( \pm 0.77)^{\mathrm{c}}$ & $14.05( \pm 1.77)^{\mathrm{b}}$ & $23.84( \pm 1.51)^{\mathrm{a}}$ \\
\hline Solubility 30 d (\% mass loss) & $0.31( \pm 0,33)^{\mathrm{c}}$ & $10.84( \pm 3.21)^{\mathrm{b}}$ & $12.70( \pm 2.99)^{\mathrm{b}}$ & $24.44( \pm 1.79)^{\mathrm{a}}$ \\
\hline
\end{tabular}

a,b,c Different letters on the same line indicate statistically significant differences between experimental groups $(p<0.05)$ 
has composition similar to the experimental sealers and TotalFill BC, and also shows high solubility ${ }^{32}$. The solubility of calcium silicate-based sealers can be related to the release of $\mathrm{OH}-$ and $\mathrm{Ca}^{2}+$ ions and these values are significantly lower in phosphate buffered saline-PBS than in distilled water ${ }^{33}$. CS-PGCH had higher solubility than CS-PG $(p<0.05)$. The larger quantity of vehicle used for the experimental sealer with polyethylene glycol and chitosan hydrogel may be related to its solubility. The addition of chitosan can affect physical and mechanical properties ${ }^{16}$. The solubility of TotalFill BC was in agreement with those observed by Tanomaru-Filho et al. ${ }^{9}$ Regarding AH Plus, the low solubility is related to its polymers promoting strong cross-links ${ }^{32}$.

The high $\mathrm{pH}$ promoted by the calcium silicate-based sealers (Table 3 ) was previously reported ${ }^{9,34}$. The properties of alkaline $\mathrm{pH}$ and calcium ion release may be related to bioactivity, induction of mineralization ${ }^{35,36}$, and antimicrobial activity $^{28}$. Thus, some solubility of calcium silicate-based materials may have an effect regarding their biological and antimicrobial activity ${ }^{31}$. In addition, the solubility test is carried out in different conditions from the clinical situation, regarding the contact between the root canal sealer and moisture from tissues in contact to the material ${ }^{37}$. Therefore, the micro-CT evaluation of volumetric stability after 7 and 30 days may complement the solubility test.

The flow of an endodontic sealer is an essential property aiming to fill irregularities in the root canals ${ }^{38}$. AH Plus, TotalFill BC and CS-PG complied with the ISO 6876:2012 ${ }^{19}$ standard that requires values above $17 \mathrm{~mm}$. Although CS$\mathrm{PGCH}$ has an average flow of $17.46 \mathrm{~mm}$, this material does not comply with the specifications of ISO $6876^{19}$, since some specimens showed flow of less than $17 \mathrm{~mm}$. An additional assessment to complement the conventional test was also performed based on a previous study ${ }^{20}$, in which the flow is measured in all area occupied by the sealers $\left(\mathrm{mm}^{2}\right)$. The experimental sealer with polyethylene glycol (CS-PG) had flow ( $\mathrm{mm}$ and $\left.\mathrm{mm}^{2}\right)$ (Table 2$)$ similar to AH Plus $(p>0.05)$, and greater than CS-PGCH $(p<0.05)$. TotalFill BC had the highest flow rate $(p<0.05)$. Our results regarding the flow of TotalFill $\mathrm{BC}$ and $\mathrm{AH}$ Plus are in agreement with Tanomaru-Filho et al. ${ }^{9}$ The flow ability of bioceramic root canal filling materials are related to their small particle size and appropriate viscosity ${ }^{39}$, while the epoxy resin in AH Plus is responsible for its high flow rate ${ }^{38}$. The association of chitosan to the experimental sealer led to a less homogeneous mixture, which can be related to its lower flow (Table 2).

Radiopacity is essential for an endodontic sealer to allows the radiographic analysis of the root canal filling quality $^{3}$. All sealers evaluated had radiopacity above $3 \mathrm{~mm} \mathrm{Al}$, in accordance with the recommendation of ISO 6876:2012 ${ }^{19}$ (Table 2). CS-PG had greater radiopacity than CS-PGCH $(p<0.05)$, and similar to TotalFill BC $(p>0.05)$. These results may be due to the greater amount of liquid present in CS-PGCH. Moreover, the presence of chitosan can affect the physical properties of the materials ${ }^{16}$. Previous studies demonstrated that zirconium oxide promotes proper radiopacity ${ }^{21}$ as radiopacifying agent for association with calcium silicatebased cements ${ }^{40}$. Húngaro-Duarte et al. ${ }^{41}$ observed that both zirconium oxide and calcium tungstate promoted proper radiopacity, in agreement with our results.

As the experimental sealer with polyethylene glycol and chitosan hydrogel had a longer setting time, less flow and radiopacity, in addition to greater solubility, this sealer was not considered suitable for clinical application. Thus, the CS-PG experimental sealer was selected for the analysis of volumetric change by micro-CT, in comparison with the commercial sealers AH Plus and TotalFill BC. Although the CS-PG had solubility above the maximum recommended by ISO $6876: 2012^{19}$, this sealer presented low volumetric change after 7 and 30 days of immersion in distilled water, with the lowest volume loss at 30 days $(p<0.05)$. CS-PG and TotalFill BC had similar volumetric change $(\mathrm{p}>0.05)$ after 7 days, and greater values than AH Plus $(p<0.05)$. At 30 days, CS-PG and AH Plus showed similar values $(p>0.05)$, and lower than TotalFill BC $(p<0.05)$ (Table 4$)$. Calcium silicate-based sealers are hydrophilic materials, capable of absorbing water. Therefore, these materials have larger difference in mass after the water has evaporated in the conventional solubility test, which is not appropriate for hydrophilic materials ${ }^{41}$. Previous studies ${ }^{8,42}$ observed that calcium silicate-based sealers presented high solubility in the conventional tests. However, different results were observed for the analysis of volumetric change. The volumetric stability of the calcium silicate sealers may be related to the absorption of fluids ${ }^{43}$. Therefore, the volumetric change methodology is important as an additional method to the conventional solubility and dimensional change tests, presenting correlation with the clinical performance of endodontic materials ${ }^{9}$.

An important limitation of the current study is that results from in vitro studies must be interpreted and extrapolated to clinical situations with caution ${ }^{44}$. Nevertheless, these preliminary results can contribute to further in vivo and clinical studies.

Table 3. $\mathrm{pH}$ values (mean and standard deviation) observed in the different experimental time intervals (3, 12 and 24 hours, 7, 14 and 21 days).

\begin{tabular}{cccccc}
\hline Periods & AH Plus & TotalFill BC & CS-PG & CS-PGCH & Control \\
\hline $3 \mathrm{~h}$ & $7.04( \pm 0.34)^{\mathrm{A}, \mathrm{c}}$ & $10.70( \pm 0.25)^{\mathrm{B}, \mathrm{a}}$ & $10.13( \pm 0.41)^{\mathrm{AB}, \mathrm{b}}$ & $10.42( \pm 0.14)^{\mathrm{AB}, \mathrm{ab}}$ & $6.15( \pm 0.29)^{\mathrm{A}, \mathrm{d}}$ \\
\hline $12 \mathrm{~h}$ & $7.42( \pm 0.38)^{\mathrm{A}, \mathrm{c}}$ & $11.39( \pm 0.33)^{\mathrm{A}, \mathrm{a}}$ & $9.78( \pm 0.41)^{\mathrm{AB}, \mathrm{b}}$ & $9.88( \pm 0.25)^{\mathrm{BC}, \mathrm{b}}$ & $6.36( \pm 0.22)^{\mathrm{A}, \mathrm{d}}$ \\
\hline $24 \mathrm{~h}$ & $6.58( \pm 0.16)^{\mathrm{B}, \mathrm{c}}$ & $10.37( \pm 0.20)^{\mathrm{B}, \mathrm{a}}$ & $9.49( \pm 0.43)^{\mathrm{B}, \mathrm{b}}$ & $9.49( \pm 0.41)^{\mathrm{C}, \mathrm{b}}$ & $6.50( \pm 0.17)^{\mathrm{A}, \mathrm{c}}$ \\
\hline $7 \mathrm{~d}$ & $5.73( \pm 0.29)^{\mathrm{C}, \mathrm{d}}$ & $10.29( \pm 0.21)^{\mathrm{B}, \mathrm{b}}$ & $10.36( \pm 0.77)^{\mathrm{AB}, \mathrm{ab}}$ & $10.93( \pm 0.54)^{\mathrm{A}, \mathrm{a}}$ & $6.39( \pm 0.42)^{\mathrm{A}, \mathrm{c}}$ \\
\hline $14 \mathrm{~d}$ & $6.44( \pm 0.43)^{\mathrm{BC}, \mathrm{b}}$ & $10.57( \pm 0.13)^{\mathrm{B}, \mathrm{a}}$ & $10.58( \pm 0.47)^{\mathrm{A}, \mathrm{a}}$ & $10.84( \pm 0.43)^{\mathrm{A,a}}$ & $6.11( \pm 0.29)^{\mathrm{A}, \mathrm{b}}$ \\
\hline $21 \mathrm{~d}$ & $6.05( \pm 0.20)^{\mathrm{C}, \mathrm{c}}$ & $9.50( \pm 0.93)^{\mathrm{C}, \mathrm{b}}$ & $10.05( \pm 0.91)^{\mathrm{AB}, \mathrm{b}}$ & $10.89( \pm 0.30)^{\mathrm{A,a}}$ & $6.08( \pm 0.34)^{\mathrm{A}, \mathrm{c}}$ \\
\hline
\end{tabular}

\footnotetext{
${ }^{\mathrm{ABC}}$ Different capital letter in the same column indicate statistically significant difference among the periods $(p<0.05)$. ${ }^{\text {abcd }}$ Different lower case letters on
}

the same row indicate statistically significant difference among the sealers $(p<0.05)$. Control = distilled water. 
Table 4. Volumetric change (7 and 30 days) (mean and standard deviation) observed in the different endodontic sealers.

\begin{tabular}{lccc}
\hline & AH Plus & TotalFill BC & CS-PG \\
\hline Volumetric change $7 \mathrm{~d}, \%$ & $1.007( \pm 0.406)^{\mathrm{A}, \mathrm{b}}$ & $-1.818( \pm 0.617)^{\mathrm{A}, \mathrm{a}}$ & $-2.052( \pm 1.324)^{\mathrm{A}, \mathrm{a}}$ \\
\hline Volumetric change $30 \mathrm{~d}, \%$ & $-0.328( \pm 0.100)^{\mathrm{B}, \mathrm{b}}$ & $-1.875( \pm 0.898)^{\mathrm{A}, \mathrm{a}}$ & $-0.347( \pm 0.174)^{\mathrm{B}, \mathrm{b}}$ \\
\hline $\begin{array}{l}\text { AB Different capital letter in the same column indicate statistically significant difference between the periods }(p<0.05) .{ }^{\text {ab }} \text { Different lower case letters on the } \\
\text { same row indicate statistically significant difference among the sealers }(p<0.05) . \text { Negative values indicate volume loss. }\end{array}$
\end{tabular}

\section{Conclusions}

Calcium silicate-based experimental endodontic sealer with polyethylene glycol presented proper setting time, radiopacity, flow and $\mathrm{pH}$, besides low volumetric change, showing better results than CS-PGCH, and potential for clinical application.

\section{Acknowledgments}

This study was supported by the Coordenação de Aperfeiçoamento de Pessoal de Nível Superior - Brazil (CAPES) - Finance Code 001, CNPq (307145/2015-8) and Fundação de Amparo à Pesquisa do Estado de São Paulo FAPESP (2017/14305-9, 2017/19049-0).

\section{References}

1. Parirokh M, Torabinejad M, Dummer PMH. Mineral trioxide aggregate and other bioactive endodontic cements: an updated overview - part I: vital pulp therapy. Int Endod J. 2018;51:177205.

2. Morejón-Alonso L, Carrodeguas RG, dos Santos LA. Effects of silica addition on the chemical, mechanical and biological properties of a new a-tricalcium phosphate/tricalcium silicate cement. Mater Res. 2011;14(4):475-82.

3. Candeiro GT, Correia FC, Duarte MA, Ribeiro-Siqueira DC, Gavini G. Evaluation of radiopacity, $\mathrm{pH}$, release of calcium ions, and flow of a bioceramic root canal sealer. J Endod. 2012;38:842-5.

4. Zhou HM, Du TF, Shen Y, Wang ZJ, Zheng YF, Haapasalo M. In vitro cytotoxicity of calcium silicate-containing endodontic sealers. J Endod. 2015;41:56-61.

5. Prati C, Gandolfi MG. Calcium silicate bioactive cements: biological perspectives and clinical applications. Dent Mater. 2015;31:351-70.

6. Athanassiadis B, Walsh LJ. Aspects of solvent chemistry for calcium hydroxide medicaments. Materials (Basel). 2017;10:1219.

7. Alves Silva EC, Tanomaru-Filho M, da Silva GF, Delfino MM, Cerri PS, Guerreiro-Tanomaru JM. Biocompatibility and bioactive potential of new calcium silicate-based endodontic sealers: Bio-C Sealer and Sealer Plus BC. J Endod. 2020;46(10):1470-77.

8. Zordan-Bronzel CL, Esteves Torres FF, Tanomaru-Filho M, Chávez-Andrade GM, Bosso-Martelo R, Guerreiro-Tanomaru JM. Evaluation of physicochemical properties of a new calcium silicate-based sealer, Bio-C Sealer. J Endod. 2019;45:1248-52.

9. Tanomaru-Filho M, Torres FFE, Chavez-Andrade GM, de Almeida M, Navarro LG, Steier L, et al. Physicochemical Properties and volumetric change of silicone/bioactive glass and calcium silicate-based endodontic sealers. J Endod. 2017;43:2097-101.

10. Rodriguez-Lozano FJ, Garcia-Bernal D, Onate-Sanchez RE, Ortolani-Seltenerich PS, Forner L, Moraleda JM. Evaluation of cytocompatibility of calcium silicate-based endodontic sealers and their effects on the biological responses of mesenchymal dental stem cells. Int Endod J. 2017;50:67-76.

11. Benetti F, de Azevedo Queiroz Í, Oliveira PHC, Conti LC, Azuma MM, Oliveira SHP, et al. Cytotoxicity and biocompatibility of a new bioceramic endodontic sealer containing calcium hydroxide. Braz Oral Res. 2019;33:e042.

12. Bueno CR, Valentim D, Marques VA, Gomes-Filho JE, Cintra LT, Jacinto RC, et al. Biocompatibility and biomineralization assessment of bioceramic-, epoxy-, and calcium hydroxidebased sealers. Braz Oral Res. 2016;30(1):e81.

13. Zordan-Bronzel CL, Tanomaru-Filho M, Rodrigues EM, Chávez-Andrade GM, Faria G, Guerreiro-Tanomaru JM. Cytocompatibility, bioactive potential and antimicrobial activity of an experimental calcium silicate-based endodontic sealer. Int Endod J. 2019;52:979-86.

14. Nair PN, Henry S, Cano V, Vera J. Microbial status of apical root canal system of human mandibular first molars with primary apical periodontitis after "one-visit" endodontic treatment. Oral Surgery, Oral Medicine, Oral Pathology, Oral Radiology, and Endodontology. 2005;99:231-52.

15. Long J, Kreft JU, Camilleri J. Antimicrobial and ultrastructural properties of root canal filling materials exposed to bacterial challenge. J Dent. 2020;93:103283.

16. Panahi F, Rabiee SM, Shidpour R. Synergic effect of chitosan and dicalcium phosphate on tricalcium silicate-based nanocomposite for root-end dental application. Mater Sci Eng C. 2017;80:63141.

17. Del Carpio-Perochena A, Kishen A, Shrestha A, Bramante CM. Antibacterial Properties Associated with Chitosan Nanoparticle Treatment on Root Dentin and 2 Types of Endodontic Sealers. J Endod. 2015;41:1353-8.

18. Budiraharjo R, Neoh KG, Kang ET, Kishen A. Bioactivity of novel carboxymethyl chitosan scaffold incorporating MTA in a tooth model. Int Endod J. 2010;43:930-9.

19. International Organization for Standardization - ISO. ISO 6876 dental root canal sealing materials. Geneva, Switzerland: ISO; 2012.

20. Tanomaru-Filho M, Silveira GF, Tanomaru JM, Bier CA. Evaluation of the thermoplasticity of different gutta-percha cones and Resilon. Aust Endod J. 2007;33:23-6.

21. Hungaro-Duarte MA, de Oliveira El Kadre GD, Vivan RR, Guerreiro Tanomaru JM, Tanomaru-Filho M, de Moraes IG. Radiopacity of portland cement associated with different radiopacifying agents. J Endod. 2009;35:737-40.

22. Carvalho-Junior JR, Correr-Sobrinho L, Correr AB, Sinhoreti MA, Consani S, Sousa-Neto MD. Solubility and dimensional change after setting of root canal sealers: a proposal for smaller dimensions of test samples. J Endod. 2007;33:1110-6.

23. Kebudi Benezra M, Schembri Wismayer P, Camilleri J. Interfacial characteristics and cytocompatibility of hydraulic sealer cements. J Endod. 2018;44:1007-17.

24. Silva Almeida LH, Moraes RR, Morgental RD, Pappen FG. Are premixed calcium silicate-based endodontic sealers comparable to conventional materials? A systematic review of in vitro studies. J Endod. 2017;43:527-35.

25. Camões IC, Salles MR, Chevitarese O, Gomes LN. Diffusion of $\mathrm{Ca}(\mathrm{OH}) 2$ associated with different vehicles: chromatographic study (high-performance liquid chromatography). J Endod. 2004;30:30-4.

26. Zhou Y, Hou DS, Jiang JY, She W, Yu J. Reactive molecular simulation on the calcium silicate hydrates/polyethylene glycol composites. Chem Phys Lett. 2017;687:184-7. 
27. Chen F, Liu C, Wei J, Chen X, Zhao Z. Preparation and characterization of injectable calcium phosphate cement paste modified by polyethylene glycol-6000. Mater Chem Phys. 2011;125(3):818-24.

28. Pires-de-Souza FCP, Moraes PC, Garcia LFR, Aguilar FG, Watanabe E. Evaluation of $\mathrm{pH}$, calcium ion release and antimicrobial activity of a new calcium aluminate cement. Braz Oral Res. 2013;27:324-30.

29. Loushine BA, Bryan TE, Looney SW, Gillen BM, Loushine RJ, Weller RN, et al. Setting properties and cytotoxicity evaluation of a premixed bioceramic root canal sealer. J Endod. 2011;37:673-7.

30. Xuereb M, Vella P, Damidot D, Sammut CV, Camilleri J. In situ assessment of the setting of tricalcium silicate-based sealers using a dentin pressure model. J Endod. 2015;41:111-24.

31. Vivan RR, Zapata RO, Zeferino MA, Bramante CM, Bernardineli $\mathrm{N}$, Garcia RB, et al. Evaluation of the physical and chemical properties of two commercial and three experimental root-end filling materials. Oral Surgery, Oral Medicine, Oral Pathology, Oral Radiology, and Endodontology. 2010;110:250-6.

32. Borges RP, Sousa-Neto MD, Versiani MA, Rached-Junior FA, De-Deus G, Miranda CE, et al. Changes in the surface of four calcium silicate-containing endodontic materials and an epoxy resin-based sealer after a solubility test. Int Endod J. 2012;45:419-28.

33. Urban K, Neuhaus J, Donnermeyer D, Schafer E, Dammaschke T. Solubility and $\mathrm{pH}$ value of 3 different root canal sealers: a long-term investigation. J Endod. 2018;44:1736-40.

34. Zhou HM, Shen Y, Zheng W, Li L, Zheng YF, Haapasalo M. Physical properties of 5 root canal sealers. J Endod. 2013;39:1281-6.

35. Duarte MA, Demarchi AC, Yamashita JC, Kuga MC, Fraga Sde C. $\mathrm{pH}$ and calcium ion release of 2 root-end filling materials. Oral Surgery, Oral Medicine, Oral Pathology, Oral Radiology, and Endodontology. 2003;95:345-7.

36. Gandolfi MG, Taddei P, Tinti A, Prati C. Apatite-forming ability (bioactivity) of ProRoot MTA. Int Endod J. 2010;43:917-29.
37. Elyassi Y, Moinzadeh AT, Kleverlaan CJ. Characterization of leachates from 6 root canal sealers. J Endod. 2019;45:623-7.

38. Bernardes RA, de Amorim Campelo A, Junior DS, Pereira LO, Duarte MA, Moraes IG, et al. Evaluation of the flow rate of 3 endodontic sealers: sealer 26, AH Plus, and MTA Obtura. Oral Surgery, Oral Medicine, Oral Pathology, Oral Radiology, and Endodontology. 2010;109:e47-9.

39. Celikten B, Uzuntas CF, Orhan AI, Orhan K, Tufenkci P, Kursun S, et al. Evaluation of root canal sealer filling quality using a single-cone technique in oval shaped canals: an In vitro Micro-CT study. Scanning. 2016;38:133-40.

40. Bosso-Martelo R, Guerreiro-Tanomaru JM, Viapiana R, Berbert FL, Duarte MA, Tanomaru-Filho M. Physicochemical properties of calcium silicate cements associated with microparticulate and nanoparticulate radiopacifiers. Clin Oral Investig. 2016;20:8390.

41. Hungaro Duarte MA, Minotti PG, Rodrigues CT, Zapata RO, Bramante CM, Tanomaru-Filho M, et al. Effect of different radiopacifying agents on the physicochemical properties of white Portland cement and white mineral trioxide aggregate. J Endod. 2012;38:394-7.

42. Torres FFE, Zordan-Bronzel CL, Guerreiro-Tanomaru JM, Chávez-Andrade GM, Pinto JC, Tanomaru-Filho M. Effect of immersion in distilled water or phosphate-buffered saline on the solubility, volumetric change and presence of voids within new calcium silicate-based root canal sealers. Int Endod J. 2020;53:385-91

43. Silva EJ, Perez R, Valentim RM, Belladonna FG, De-Deus GA, Lima IC, et al. Dissolution, dislocation and dimensional changes of endodontic sealers after a solubility challenge: a micro-CT approach. Int Endod J. 2017;50:407-14.

44. Williamson AE, Dawson DV, Drake DR, Walton RE, Rivera EM. Effect of root canal filling/sealer systems on apical endotoxin penetration: a coronal leakage evaluation. J Endod. 2005;31:599-604. 